\title{
Article \\ Mechanical Properties of Cement Composites Using Modified Plastics by Gamma Irradiation
}

\author{
Hyeonwook Cheon ${ }^{1}$, Jamshid Ruziev ${ }^{1}$, Heonseok Lee ${ }^{1} \mathbb{D}$, Yonghak Kang ${ }^{2} \mathbb{D}$, Seungjun Roh $^{3}(\mathbb{D})$ and \\ Woosuk Kim ${ }^{3, * \text { (D) }}$ \\ 1 Department of Architectural Engineering, Kumoh National Institute of Technology, Gumi 39177, Korea; \\ chw0619@kumoh.ac.kr (H.C.); ruziev@kumoh.ac.kr (J.R.); lhs@kumoh.ac.kr (H.L.) \\ 2 International Business Division, New Business Development Team, Korea Conformity Laboratories, \\ Seoul 06711, Korea; yhkang@kcl.re.kr \\ 3 School of Architecture, Kumoh National Institute of Technology, Gumi 39177, Korea; roh@kumoh.ac.kr \\ * Correspondence: kimw@kumoh.ac.kr; Tel.: +82-54-478-7591
}

check for updates

Citation: Cheon, H.; Ruziev, J.; Lee, H.; Kang, Y.; Roh, S.; Kim, W. Mechanical Properties of Cement Composites Using Modified Plastics by Gamma Irradiation. Appl. Sci. 2021, 11, 11982. https://doi.org/ 10.3390/app112411982

Academic Editors: Auxi Barbudo,

Adela P. Galvín and Manuel

Cabrera Montenegro

Received: 31 October 2021

Accepted: 13 December 2021

Published: 16 December 2021

Publisher's Note: MDPI stays neutral with regard to jurisdictional claims in published maps and institutional affiliations.

Copyright: (c) 2021 by the authors. Licensee MDPI, Basel, Switzerland. This article is an open access article distributed under the terms and conditions of the Creative Commons Attribution (CC BY) license (https:// creativecommons.org/licenses/by/ $4.0 /)$.

\begin{abstract}
Recently, pollution caused by an increasing amount of worldwide plastic waste has become a global problem. However, these concerns can be alleviated by the use of gamma-ray technology. Using radiation technology, plastic wastes can be converted into a variety of useful purposes presenting powerful opportunities for environmental sustainability and material innovations. Plastics are strong, durable, waterproof, lightweight, easy to mold, and recyclable. In this study, plastic aggregate modified by gamma irradiation was mixed into cement composites, and mechanical property evaluation experiments were conducted. As a result, it was confirmed that the physical performance of cement composites was improved by up to $70 \%$ in the case of using the modified plastic aggregates compared to the general plastic aggregate.
\end{abstract}

Keywords: modified plastic; lightweight aggregate; gamma-irradiation; cement composites

\section{Introduction}

Recently, the demand for high strength and lightness of construction members has been increasing due to the progress of large-scale construction structures. Previous studies have shown that the strength of cement composites follows by inducing a reduction in the unit volume mass of the lightweight cement composites [1-4]. In general, in order to induce the weight of cement composites, there is a method of using lightweight aggregates. Studies related to methods for weight reduction using lightweight aggregates such as rubber lightweight aggregates and plastic lightweight aggregates are being actively conducted. Among them, plastic aggregates seem to need measures to recycle such plastics, as the use of plastic containers has increased due to the recent spread and prolonged coronavirus, resulting in more plastic waste. Since waste plastics have relatively high strength and small unit volume, they appear to have advantageous aggregate properties to produce lightweight cement composites, but plastic aggregates have disadvantageous surface properties [5,6]. In order to use plastic aggregates in a more efficient way, it is applied to various fields such as medicine, bio, industry, environment, and construction. Based on prior research, gamma-ray irradiation technology was applied to induce and reform cross-linkage of plastic pellets to be used as aggregates [7,8]. According to Choi et al. (2007), the method of grafting radiation to a polymer material improves its physical, chemical and mechanical properties, and it is described as an economical and eco-friendly method. Moreover, Lee et al. (2008) stated that as the gamma irradiation dose increases, there is an increase in tensile stress and compressive stress in a plastic region, and Lee et al. (1999) described an increase in abrasion resistance of an ultra-high molecular weight composite irradiated with gamma rays. 
The method of using gamma irradiation technology is eco-friendly and can improve the physical, chemical, and mechanical properties of polymer materials. Conversely, due to the lack of gamma-ray irradiation facilities domestically and internationally, it is expensive to irradiate gamma rays. Therefore, it is judged that it is necessary to develop a plan to use the natural radiation generated from the solar rays and to measure the irradiation dose for it.

There have been no studies on evaluating physical properties of modified plastic aggregates using gamma-ray irradiation applied to cement composites. Therefore, gamma rays were irradiated onto plastic types such as poly propylene (PP), poly ethylene (PE), and acrylonitrile butadiene styrene (ABS) pellets. As a result, the surface modification of the plastic aggregates was analyzed. The purpose of this study was to evaluate the suitability of the modified plastic aggregate technology by conducting unit volume mass and flexural/compressive strength tests of cement composites that secured strength and lightness by applying modified plastic aggregates through gamma irradiation.

In this study, poly propylene (PP), poly ethylene (PE), and acrylonitrile butadiene (ABS) pellets, which are recently most commonly used as plastic containers, were manufactured by extrusion method. By using this, a lightweight cement composite was manufactured to evaluate the physical performance, and in order to determine the cause, the change in surface properties of plastic aggregate according to gamma ray irradiation was analyzed.

\section{Materials and Method}

\subsection{Material properties}

\subsubsection{Physical Performance of Plastics}

In this study, a cement composite was manufactured by using ISO standard yarn for a basic aggregate and replacing plastic pellets in the form of aggregate. The plastic aggregates used for the experiment were shown in Figure 1, and it was supplied by the Korea Plastics Single Material Association. Based on previous studies, among plastic aggregate types, the reason of choosing $\mathrm{PP}$ is the occurrence of decomposition effects and, in the case of PE, a crosslinking phenomenon that occurs while there is no change in ABS when gamma-ray irradiation was applied. Each plastic has the lowest specific gravity of 0.92 in the case of PP, PE has a specific gravity of 0.94 , and ABS has a high specific gravity of 1.04 .

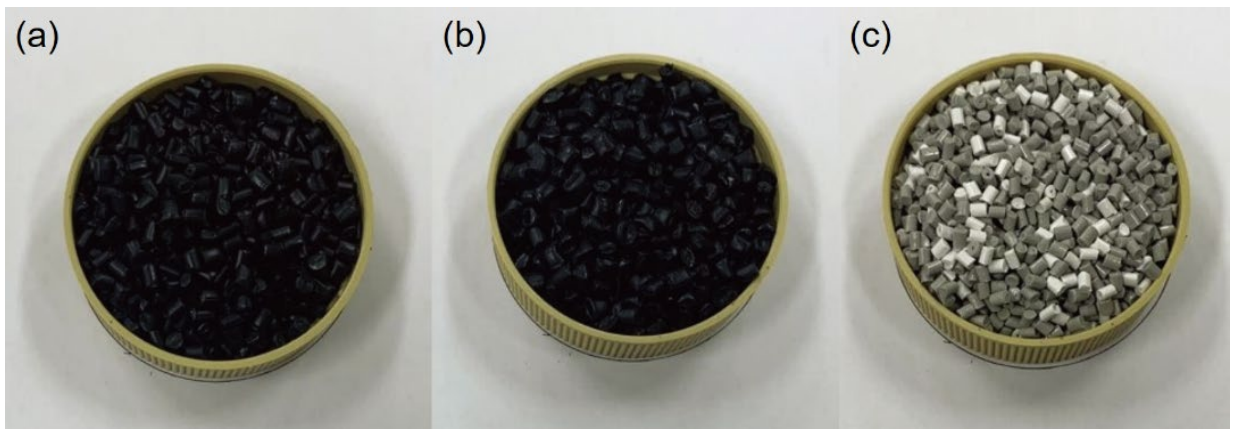

Figure 1. Plastic pellets: (a) PP (polypropylene); (b) PE (polyethylene); (c) ABS (acrylonitrile butadiene styrene).

\subsubsection{Modified Plastics by Gamma Irradiation}

In this study, plastic aggregates were modified by gamma irradiation on plastics. According to the previous study, it was confirmed that gamma irradiation on carbon composites results in cross-linkage in plastics and changing the properties of carbon composites, i.e., plastics $[9,10]$. In addition, the degree of crosslinking reaction varies depending on the irradiation dose of gamma rays, and some types of plastic may be resistant, although they may be subjected to cross-sectional decomposition depending on the type of plastic. Accordingly, the experiment was conducted using plastics such as PP 
(poly propylene) and PE (poly ethylene), which are plastic materials that appear to be crosslinking or decomposition reactions.

\subsection{Gamma Irradiation Procedure}

PP (poly propylene), PE (poly ethylene), and ABS (acrylonitrile butadiene styrene) pellets were used as substitution materials with $50 \%$ substitution for each type of plastic pellet considering the density of the materials. In the case of plastics irradiated with gamma rays, there was no change in the unit volume mass of plastics; thus, the calculation was carried out using the unit volume mass of ordinary plastics.

\subsection{Subject of the Study}

In this study, three types of plastics were used to check whether the modified plastic aggregates improved the physical performance of cement composites according to the gamma-irradiation dose for each plastic aggregate, and for the gamma-irradiation dose, the plastic irradiated with doses of 0,25, 50,75 and $100 \mathrm{kGy}$ was substituted for the cement composite to prepare a specimen. Details of each specimen are shown in Table 1.

Table 1. The list of specimens.

\begin{tabular}{|c|c|c|c|c|c|}
\hline Specimen & W/C (\%) & B:A & Substitution Rate (\%) & Plastic Type & Irradiation Dose (kGy) \\
\hline Plain & 50 & 3.6 & 50 & $\mathrm{~N}$ & $\mathrm{~N}$ \\
\hline PP-50-0 & 50 & 3.6 & 50 & PP & $\mathrm{N}$ \\
\hline PP-50-25 & 50 & 3.6 & 50 & PP & 25 \\
\hline PP-50-50 & 50 & 3.6 & 50 & PP & 50 \\
\hline PP-50-75 & 50 & 3.6 & 50 & PP & 75 \\
\hline PP-50-100 & 50 & 3.6 & 50 & PP & 100 \\
\hline PE-50-0 & 50 & 3.6 & 50 & PE & $\mathrm{N}$ \\
\hline PE-50-25 & 50 & 3.6 & 50 & PE & 25 \\
\hline PE-50-50 & 50 & 3.6 & 50 & PE & 50 \\
\hline PE-50-75 & 50 & 3.6 & 50 & PE & 75 \\
\hline PE-50-100 & 50 & 3.6 & 50 & PE & 100 \\
\hline ABS-50-0 & 50 & 3.6 & 50 & ABS & 0 \\
\hline ABS-50-25 & 50 & 3.6 & 50 & ABS & 25 \\
\hline ABS-50-50 & 50 & 3.6 & 50 & ABS & 50 \\
\hline ABS-50-75 & 50 & 3.6 & 50 & ABS & 75 \\
\hline ABS-50-100 & 50 & 3.6 & 50 & ABS & 100 \\
\hline
\end{tabular}

PP-50-0: PP $\rightarrow$ substituted for plastic; ( $\mathrm{PE} \rightarrow$ substituted for $\mathrm{PE}, \mathrm{ABS} \rightarrow$ substituted for $\mathrm{ABS}$ ); $50 \rightarrow$ substitution rate; $0 \rightarrow$ gamma radiation dose $(25 \rightarrow 25 \mathrm{kGy}, 50 \rightarrow 50 \mathrm{kGy}, 75 \rightarrow 75 \mathrm{kGy}, 100 \rightarrow 100 \mathrm{kGy}) ; \mathrm{W} / \mathrm{C}:$ water-cement ratio.

\subsection{Cement Composite Mixing Ratio Design}

For the cement composite mixing ratio, the standard formulation of KS L ISO 679 was applied, and the mixing ratio of this experiment is as shown in Table 2. The water-cement ratio was $50 \%$, the cement to aggregate ratio was 1:3.6, and the plastic aggregate was mixed in a volume ratio of $50 \%$.

Table 2. Mixing ratio by substitution of plastic pellets.

\begin{tabular}{ccccccc}
\hline \multirow{2}{*}{ Series } & \multirow{2}{*}{ Cement $\left(\mathbf{k g} / \mathbf{m}^{3}\right)$} & Water $\left(\mathbf{k g} / \mathbf{m}^{3}\right)$ & \multicolumn{4}{c}{ Fine Aggregate $\left(\mathbf{k g} / \mathbf{m}^{3}\right)$} \\
\cline { 3 - 6 } & & Sand & PP & PE & ABS \\
\hline Plain & & 1524 & 0 & 0 & \\
PP-50 & 508 & 254 & & 268.6 & 0 \\
PE-50 & & 762 & 0 & 272.98 & \\
ABS-50 & & & & 0 & 303.63 \\
\hline
\end{tabular}




\subsection{Experimental Design and Methods}

The specimens were cured for 7 and 28 days after fabrication to compare initial strength and long-term strength. Compressive strength and flexural strength tests of cement composites were performed according to KS L ISO 679, and the unit volume mass of the specimen was evaluated according to KS F 2476.

\subsubsection{Flexural Strength Evaluation}

In this study, 6 specimens for each type of plastic pellet cured for 7 and 28 days were produced such for the flexural test in accordance with KSL ISO 679. The size of specimens was $40 \times 40 \times 160 \mathrm{~mm}$, and the load was applied to the center of the specimen at a rate of $3 \mathrm{kN} / \mathrm{min}$ by load control method. In order to evaluate the ductile behavior of the specimens according to the type of plastic pellet and gamma radiation dose, the loading was continued after the peak load until it decreased to less than $80 \%$ of the maximum strength. Test set-up for the flexural strength evaluation is shown in Figure 2.

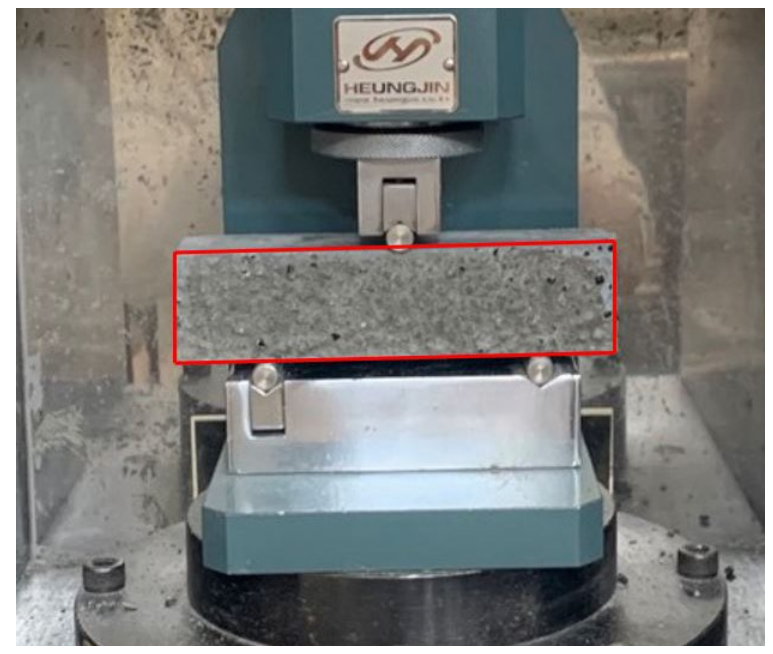

Figure 2. Flexural strength test set-up.

The flexural strength was calculated by Equation (1) in two-point load according to KS L ISO 679 obtaining up to two significant digits.

$$
f_{r}=\frac{1.5 P l}{b h^{2}}
$$

Here, $P$ : Flexural load (N);

$l$ : Span length (mm);

$b$ : Width of section (mm);

$h$ : Height of section (mm).

\subsubsection{Compression Strength Evaluation}

Similar to the flexural strength evaluation, 6 specimens for each type of plastic pellet cured for 7 and 28 days were produced such for the compression test in accordance with KSL ISO 679. However, the size of specimens was $40 \times 40 \times 40 \mathrm{~mm}$. The load was applied at a rate of $90 \mathrm{kN} / \mathrm{min}$ by load control method. Test set-up for the compression strength evaluation is shown in Figure 3. 


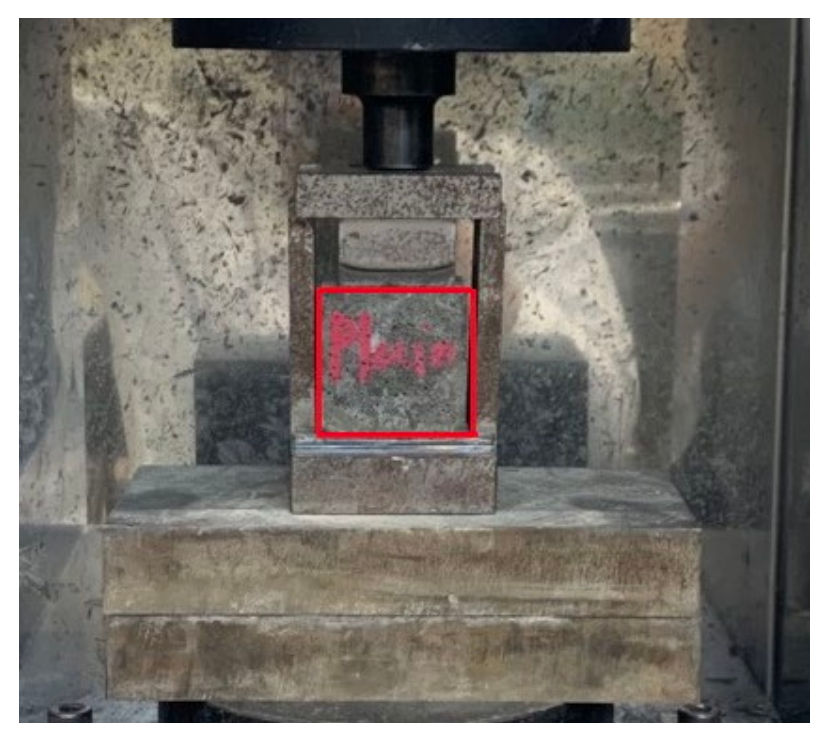

Figure 3. Compressive strength test set-up.

The compression strength was calculated by Equation (2) according to KS L ISO 679, obtaining up to two significant digits.

$$
f_{c k}=\frac{P}{A}
$$

Here, $P$ : Compressive load $(\mathrm{N})$;

$A$ : Span length $\left(\mathrm{mm}^{2}\right)$.

\subsubsection{Unit Volume Mass Measurement}

The unit volume mass was measured in accordance with KS F 2476, and it was measured as the average value of two tests in total. Since gamma rays to waste plastic aggregates do not change the specific gravity of plastic aggregates, the unit volume mass was measured by proceeding with plastics that were not irradiated with gamma rays.

The unit volume mass was calculated by Equation (3) according to KS F 2476 obtaining up to three significant digits.

$$
M=\frac{W}{V}
$$

Here, $M$ : Unit volume weight $\left(\mathrm{t} / \mathrm{m}^{3}\right)$;

$W$ : Span length (t);

$V$ : Specimen volume $\left(\mathrm{m}^{3}\right)$.

\subsubsection{SEM Analysis}

SEM (scanning electron microscopy) is an abbreviation for a scanning electron microscope with a function of directly observing a three-dimensional structure by scanning the surface of a sample with electron beams. In this experiment, the effect of gamma ray irradiation in plastic aggregates was evaluated using 100, 500, and 2000 magnification analysis conditions, and the cause of physical performance improvement of the plastic aggregate-substituted cement composite according to the gamma ray irradiation dose was determined. The samples for SEM analysis are shown in Figure 4, and the analysis conditions are shown in Table 3. 


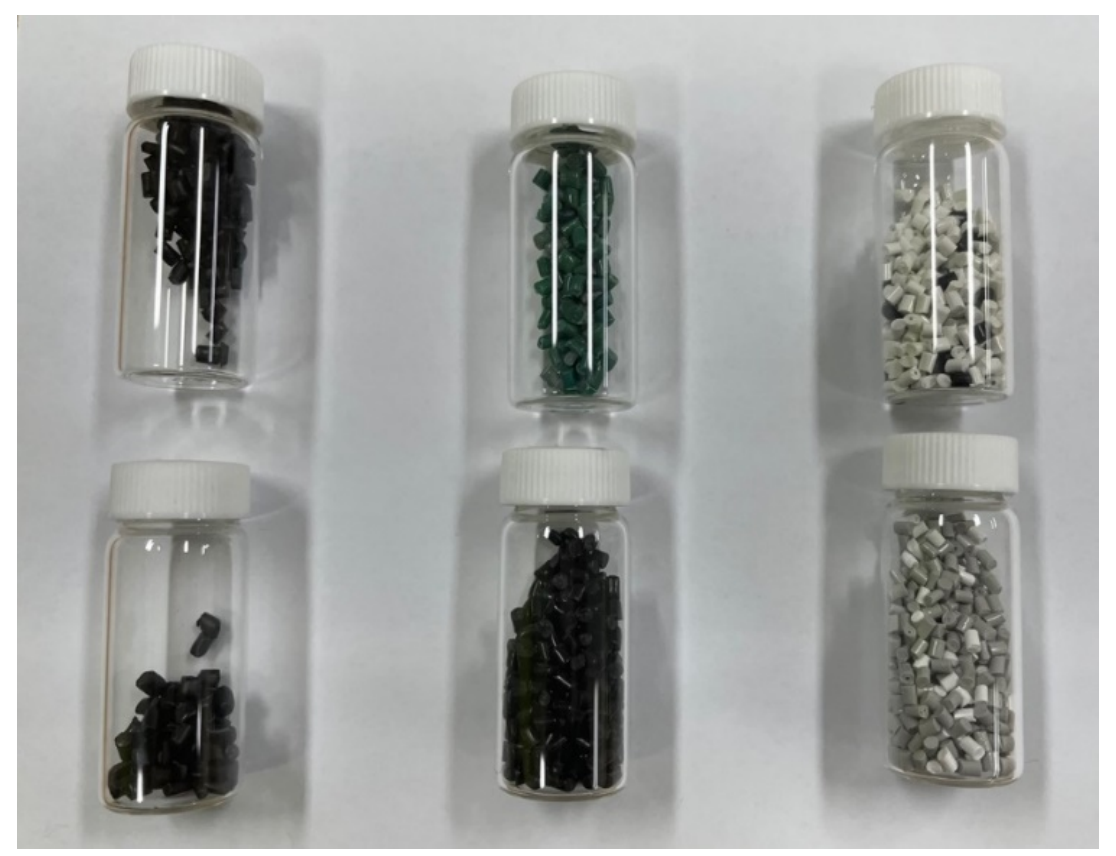

Figure 4. Prepared plastic aggregates for SEM analysis.

Table 3. SEM analyzing method of plastic aggregates.

\begin{tabular}{cc}
\hline SEM Category & Measurement Condition \\
\hline Acceleration Voltage & $15.0 \mathrm{kV}$ \\
Working Distance & $9.8 \mathrm{~mm}, 9.9 \mathrm{~mm}, 10.0 \mathrm{~mm}, 10.6 \mathrm{~mm}, 10.7 \mathrm{~mm}$, \\
Magnification & $11.2 \mathrm{~mm}$ \\
Spot Size & $\times 100, \times 500, \times 2000$ \\
Coating & $100 \mu \mathrm{m}$ \\
\hline
\end{tabular}

\subsubsection{XRD Analysis}

$\mathrm{XRD}$ is a method of analyzing a crystal structure using X-ray diffraction by $\mathrm{X}$-ray diffraction analysis. From the $X$-ray diffraction pattern obtained when the $X$-ray incident on the crystalline sample satisfies Bragg's law, the crystal structure of the compound and the elements constituting the sample can be identified and quantitatively analyzed. The analysis conditions used in the experiment are shown in Table 4.

Table 4. XRD analyzing method of plastic aggregates.

\begin{tabular}{cc}
\hline XRD Category & Measurement Condition \\
\hline X-ray Generator & $18 \mathrm{~kW}$ \\
Tube Power & $45 \mathrm{kV}, 200 \mathrm{~mA}$ \\
Scanning Speed & 4 \\
Scanning Type & Continuous \\
Range $(\theta)$ & Scanning \\
Monochrometer & $5 \sim 50^{\circ}$ \\
\hline
\end{tabular}

The sample used in the XRD analysis was analyzed using a PP plastic sample among three samples. 


\section{Experimental Results and Consideration}

3.1. Flexural Strength of Cement Composites According to the Type of Plastic Pellet and Gamma Irradiation Dose

Flexural Test Results

Table 5 and Figure 5 show the flexural test results of specimens according to the type of plastic pellet and gamma irradiation dose. As a result of the flexural strength test, as the curing period increased, the strength increased. However, it seems that only some samples affected by gamma ray irradiation, and it presents a tendency such as showing high strength even when a plastic not irradiated with gamma ray is used as a substitute. From this point of view, it is determined that gamma irradiation does not have a significant effect on flexural strength.

Table 5. Flexural strength of specimens according to gamma-irradiation.

\begin{tabular}{|c|c|c|c|c|c|}
\hline \multirow[t]{2}{*}{ Specimen } & \multirow[t]{2}{*}{ Irradiation Dose (kGy) } & \multicolumn{2}{|c|}{ Flexural Strength (MPa) } & \multicolumn{2}{|c|}{$\begin{array}{c}\text { Increase Rate Compared to Nonirradiated } \\
\text { Specimen }(\%)\end{array}$} \\
\hline & & 7 Days & 28 Days & 7 Days & 28 Days \\
\hline Plain & - & 7.27 & 9.93 & - & - \\
\hline PP-50-0 & 0 & 3.16 & 4.10 & - & - \\
\hline PP-50-25 & 25 & 3.52 & 3.98 & 11.39 & -2.93 \\
\hline PP-50-50 & 50 & 3.87 & 4.31 & 22.47 & 5.12 \\
\hline PP-50-75 & 75 & 4.38 & 4.80 & 38.61 & 17.07 \\
\hline PP-50-100 & 100 & 4.14 & 4.50 & 31.01 & 9.76 \\
\hline PE-50-0 & 0 & 3.67 & 4.70 & - & - \\
\hline PE-50-25 & 25 & 3.67 & 4.13 & - & -12.13 \\
\hline PE-50-50 & 50 & 3.91 & 4.03 & 6.54 & -14.26 \\
\hline PE-50-75 & 75 & 4.53 & 4.31 & 24.43 & -8.30 \\
\hline PE-50-100 & 100 & 4.14 & 6.28 & 12.81 & 33.62 \\
\hline ABS-50-0 & 0 & 3.44 & 3.75 & - & - \\
\hline ABS-50-25 & 25 & 3.67 & 4.59 & 6.69 & 22.4 \\
\hline ABS-50-50 & 50 & 4.22 & 5.72 & 22.67 & 52.53 \\
\hline ABS-50-75 & 75 & 4.30 & 5.25 & 25 & 40.00 \\
\hline ABS-50-100 & 100 & 4.14 & 4.69 & 20.35 & 25.07 \\
\hline
\end{tabular}

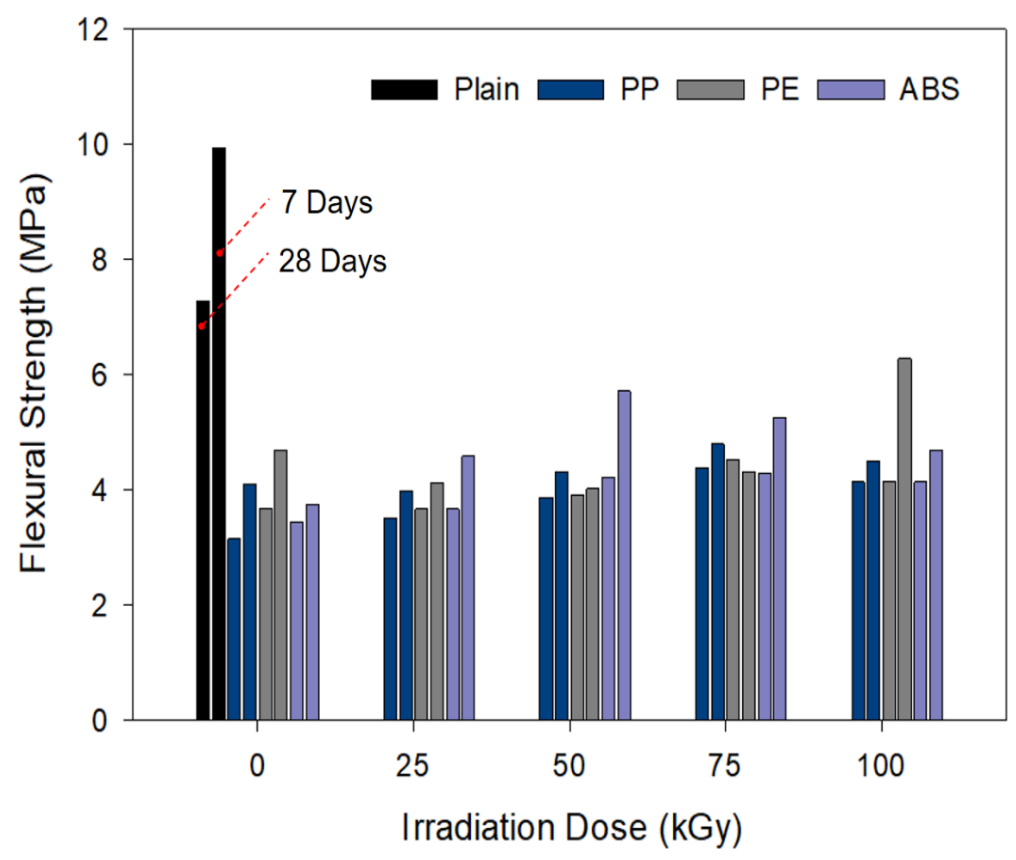

Figure 5. Flexural strength of specimens according to plastic pellets. 
3.2. Compressive Strength of Cement Composites According to the Type of Plastic Pellet and Gamma Irradiation Dose

Compressive Test Results

Table 6 and Figure 6 show the compressive strength test results of cement composites according to the type of plastic pellets and the amount of gamma irradiation.

Table 6. Compressive strength of specimens according to gamma-irradiation.

\begin{tabular}{|c|c|c|c|c|c|}
\hline \multirow[t]{2}{*}{ Specimen } & \multirow[t]{2}{*}{ Irradiation Dose (kGy) } & \multicolumn{2}{|c|}{ Compressive Strength (MPa) } & \multicolumn{2}{|c|}{$\begin{array}{l}\text { Increase Rate Compared to } \\
\text { Nonirradiated Specimen (\%) }\end{array}$} \\
\hline & & 7 Days & 28 Days & 7 Days & 28 Days \\
\hline Plain & - & 33.81 & 39.5 & - & - \\
\hline PP-50-0 & 0 & 16.15 & 20.48 & - & - \\
\hline PP-50-25 & 25 & 17.04 & 23.32 & 5.51 & 13.87 \\
\hline PP-50-50 & 50 & 17.94 & 25.69 & 11.08 & 25.44 \\
\hline PP-50-75 & 75 & 20.56 & 30.00 & 27.31 & 46.48 \\
\hline PP-50-100 & 100 & 18.77 & 29.90 & 16.22 & 46.00 \\
\hline PE-50-0 & 0 & 16.08 & 20.63 & - & - \\
\hline PE-50-25 & 25 & 16.65 & 25.53 & 3.54 & 23.75 \\
\hline PE-50-50 & 50 & 17.23 & 25.76 & 7.15 & 24.87 \\
\hline PE-50-75 & 75 & 18.31 & 35.84 & 13.87 & 73.73 \\
\hline PE-50-100 & 100 & 17.65 & 29.7 & 9.76 & 43.97 \\
\hline ABS-50-0 & 0 & 19.00 & 22.60 & - & - \\
\hline ABS-50-25 & 25 & 19.17 & 30.98 & 0.89 & 37.08 \\
\hline ABS-50-50 & 50 & 20.06 & 29.81 & 5.58 & 31.90 \\
\hline ABS-50-75 & 75 & 22.94 & 31.76 & 20.74 & 40.53 \\
\hline ABS-50-100 & 100 & 22.23 & 29.56 & 17.00 & 30.80 \\
\hline
\end{tabular}

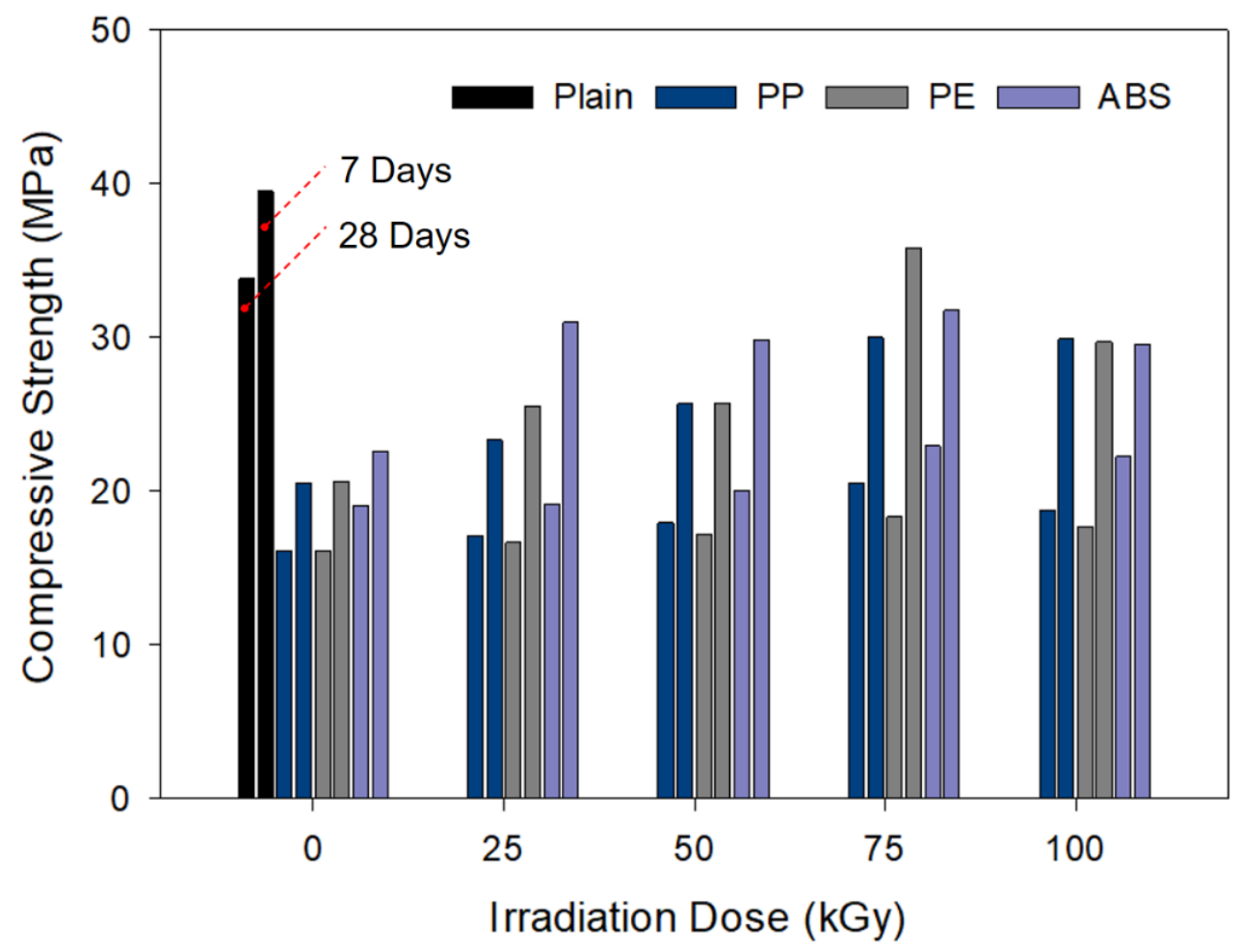

Figure 6. Compressive strength of specimens according to plastic pellets. 
As a result of the compressive strength test, it was confirmed that the strength decreased in the plastic-substituted cement composite compared to the cement composite in which the sand was not replaced with plastic.

In the case of the 7-day curing period, it was confirmed that the overall compressive strength increased moderately with the increase in the irradiation dose, and in the case of the 28-day curing period, the compressive strength of some specimens increased rapidly according to the increase in the irradiation dose.

In addition, in the case of PP and PE aggregates, the compressive strength gradually increased up to the irradiation dose of $75 \mathrm{kGy}$, but it was found that the strength decreased at $100 \mathrm{kGy}$. Conversely, in the case of ABS, the overall compressive strength increased according to gamma irradiation, but it was found to increase randomly without any particular trend according to the increase in irradiation dose.

In order to confirm the ductile behavior of specimens, Figure 7 describes the compressive stress-strain graph analyses. When the plastic aggregates irradiated with gamma ray is mixed into the specimen, it shows a lower strain rate and high compressive strength compared to the specimen substituted with the plastic aggregate that is not irradiated with gamma ray. In the case of PP, it was confirmed that the specimen substituted with modified plastic aggregate through $75 \mathrm{kGy}$ gamma-ray irradiation exhibited the compressive strength of $30.02 \mathrm{MPa}$. There was an increase by about $15 \mathrm{MPa}$ for the specimen substituted with PE modified plastic aggregate through 75 kGy gamma-ray. Moreover, the compressive strength reached to $31.76 \mathrm{MPa}$ when the ABS modified plastic aggregate, which is irradiated with $75 \mathrm{kGy}$ gamma-ray irradiation, was mixed into the specimen.

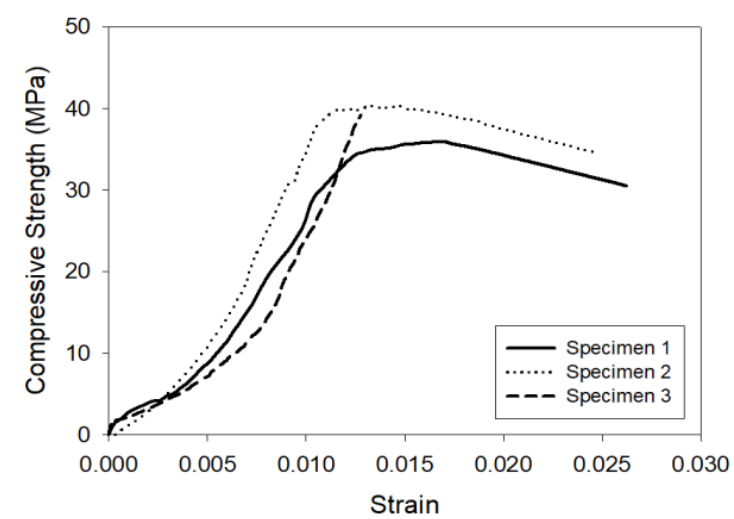

(a) Plain

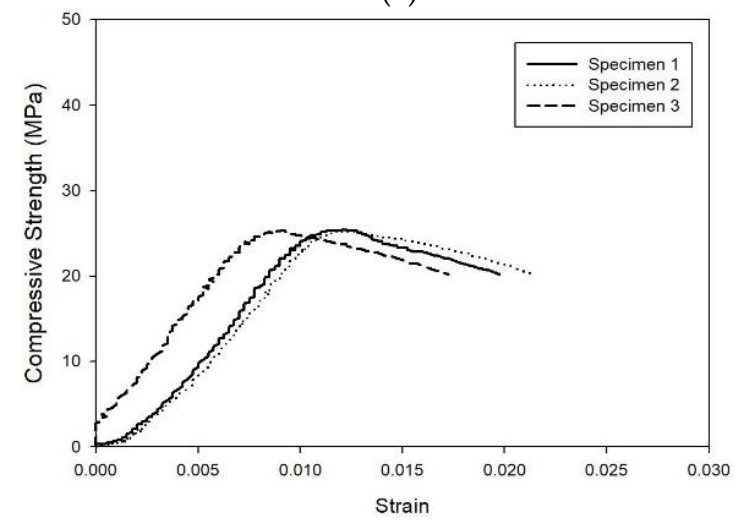

(c) PP-50-25 kGy

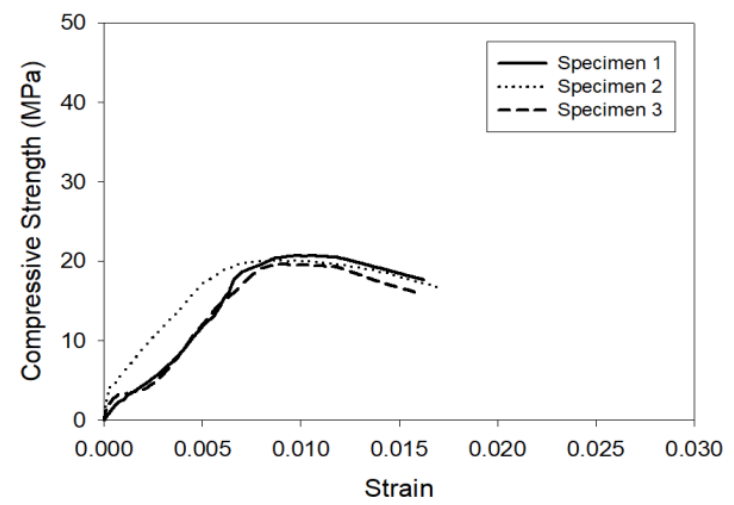

(b) PP-50-0 kGy

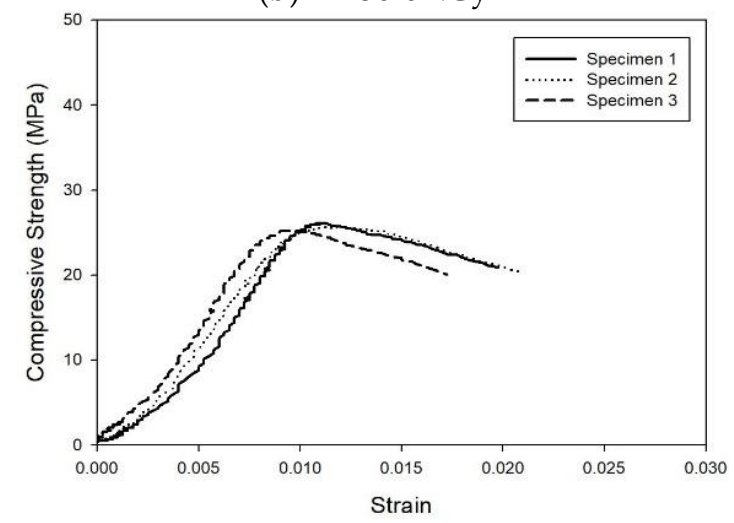

(d) PP-50-50 kGy

Figure 7. Cont. 


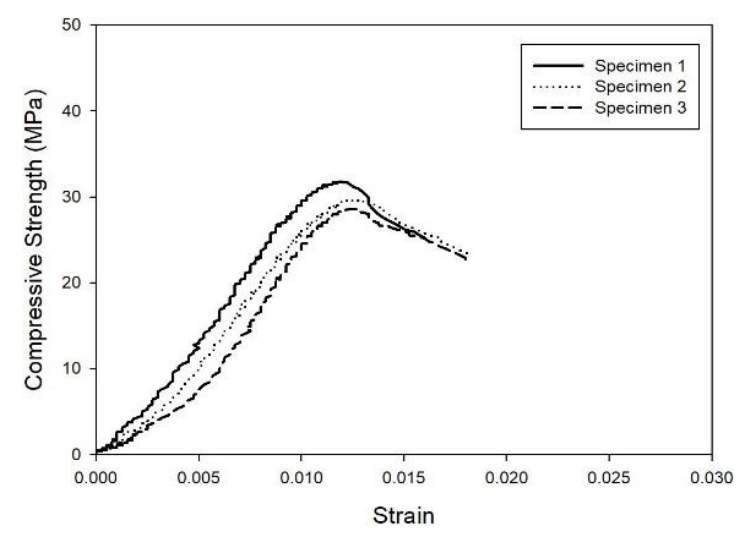

(e) PP-50-75 kGy

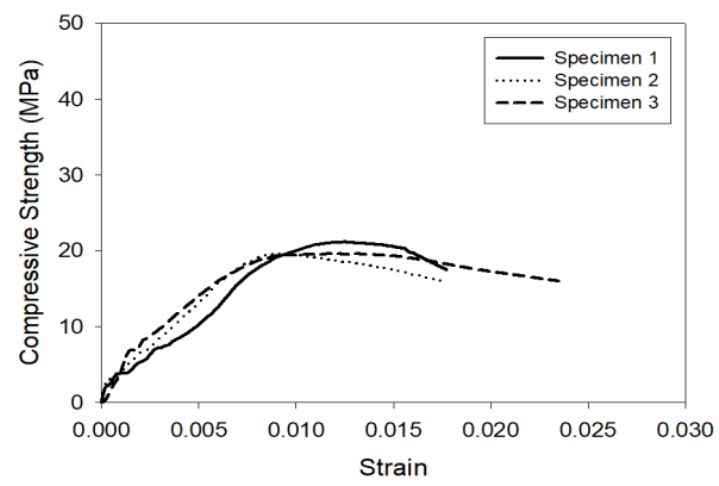

(g) PE-50-0 kGy

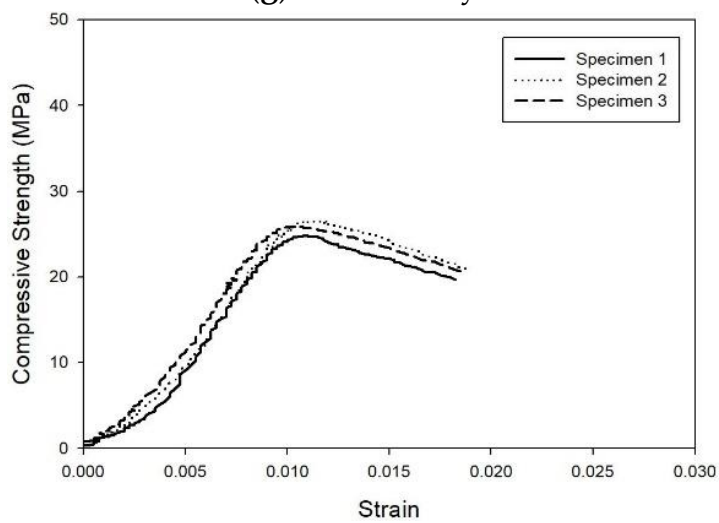

(i) PE-50-50 kGy

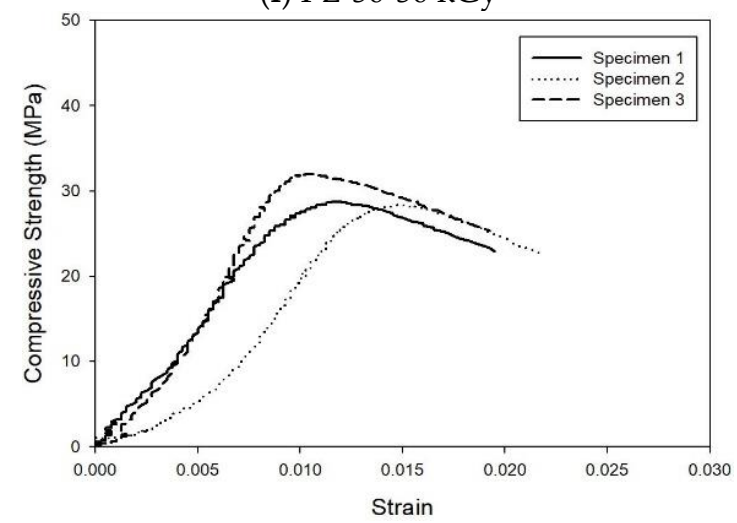

(k) PE-50-100 kGy

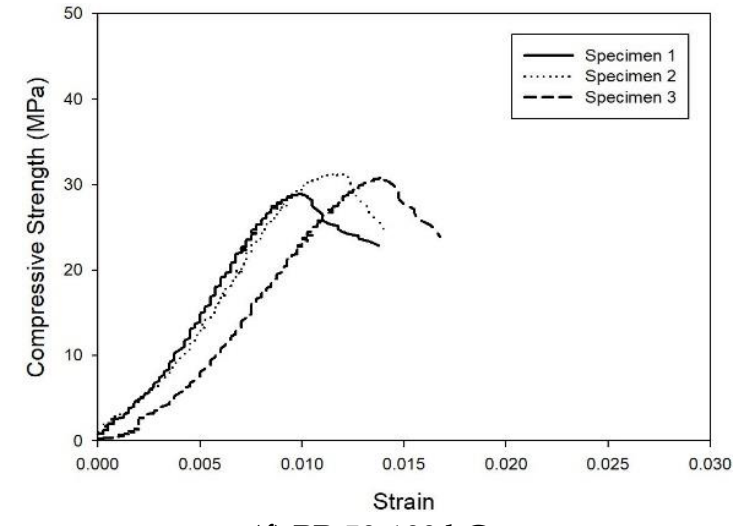

(f) PP-50-100 kGy

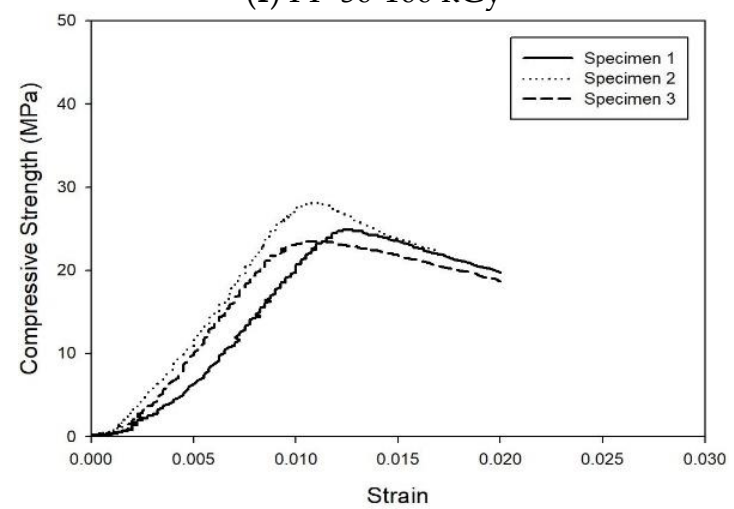

(h) PE-50-25 kGy

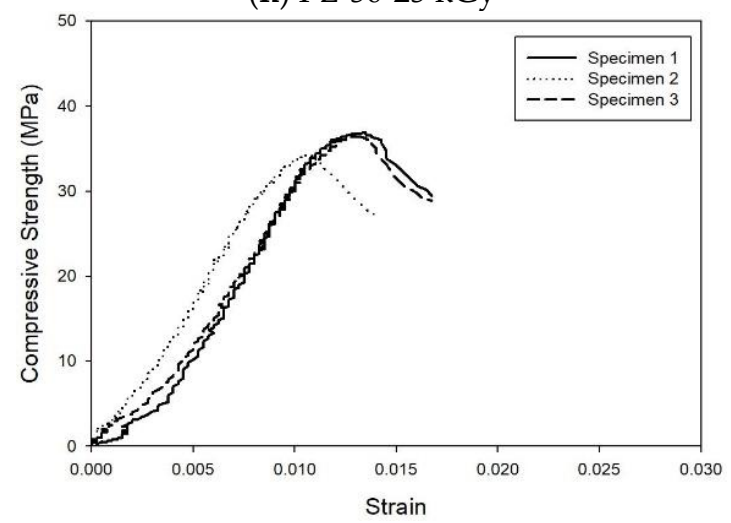

(j) PE-50-75 kGy

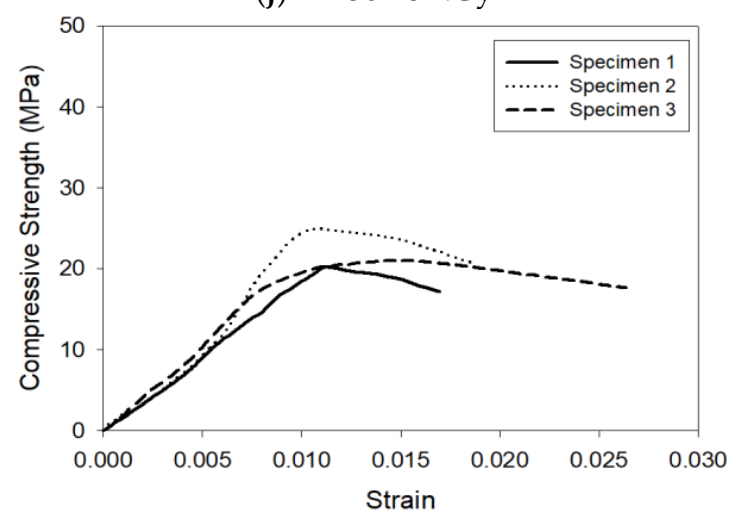

(1) ABS-50-0 kGy

Figure 7. Cont. 


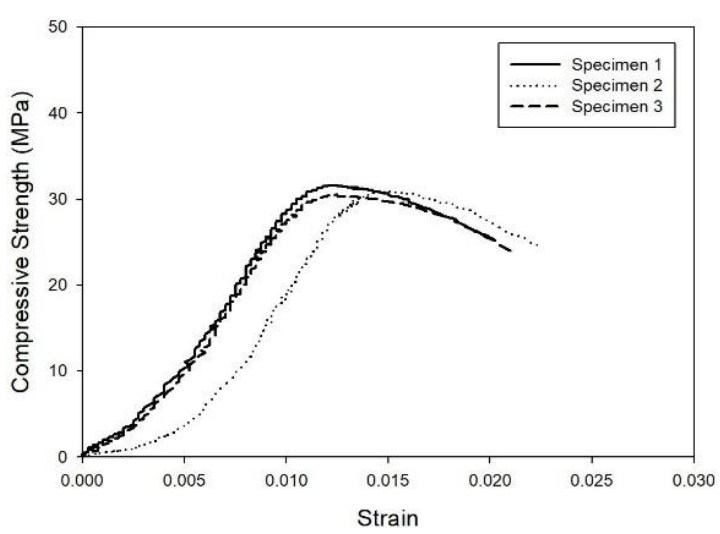

(m) ABS-50-25 kGy

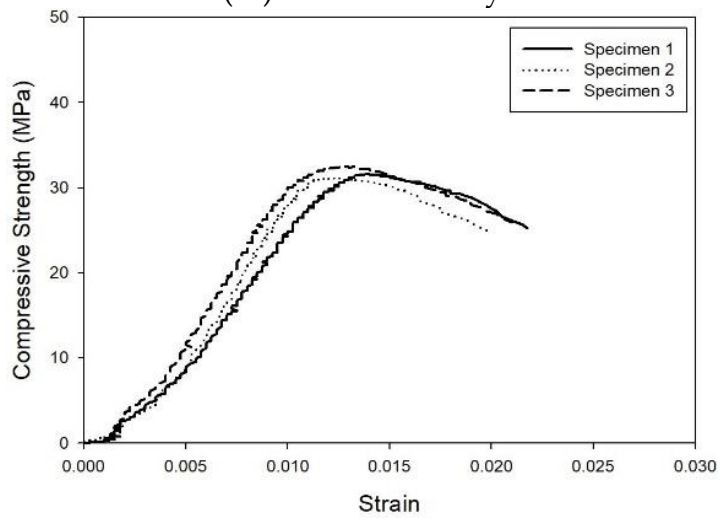

(o) ABS-50-75 kGy

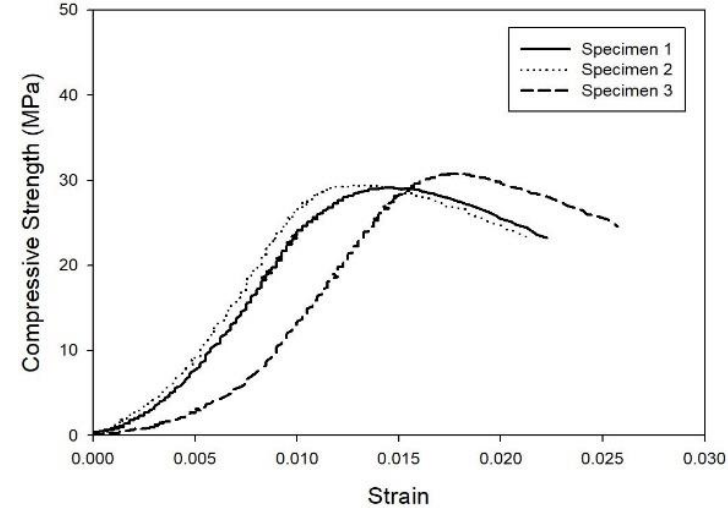

(n) ABS-50-50 kGy

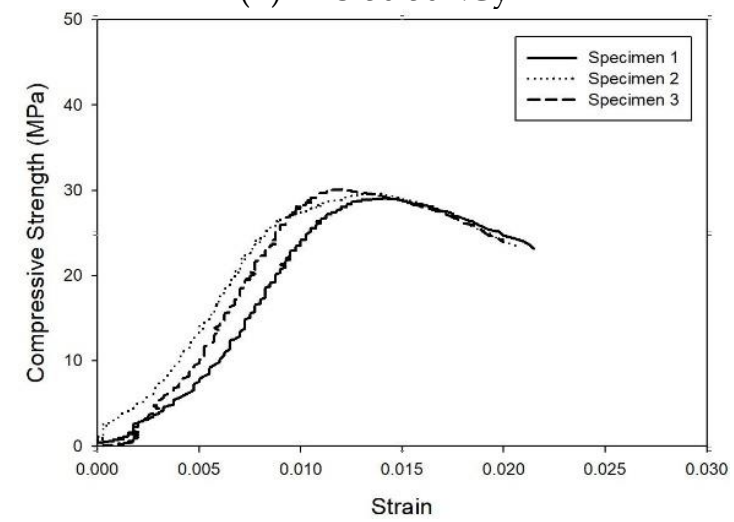

(p) ABS-50-100 kGy

Figure 7. Compressive strength strain curve of cement composites according to plastic aggregates type and gamma irradiation dose: (a) Plain; (b) PP-50-0 kGy; (c) PP-50-25 kGy; (d) PP-50-50 kGy; (e) PP-50-75 kGy; (f) PP-50-100 kGy; (g) PE-50-0 kGy; (h) PE-50-25 kGy; (i) PE-50-50 kGy; (j) PE-50-75 kGy; (k) PE-50-100 kGy; (1) ABS-50-kGy; (m) ABS-50-25 kGy; (n) ABS-50-50 kGy; (o) ABS-50-75 kGy; (p) ABS-50-100 kGy.

\subsection{Unit Volume Mass of Cement Composites According to the Type of Plastic Pellet}

When the plastic pellets were irradiated with gamma rays, there was no change in the mass of the unit volume. Therefore, the plastic pellets that were not irradiated with gamma rays were substituted to produce a specimen, and the mass of the unit volume of the specimen was measured. As a result, the unit volume mass was reduced by $20 \%$ compared to the Plain test specimen, which seems to have a definite effect on the weight reduction of the construction member. The unit volume weight of each specimen was measured, and they are shown in Figure 8 and Table 7.

Table 7. Unit volume weight of specimens according to plastic type.

\begin{tabular}{ccccc}
\hline Series & Plain & PP-50 & PE-50 & ABS-50 \\
\hline Unit volume weight $\left(\mathrm{t} / \mathrm{m}^{3}\right)$ & 2.148 & 1.711 & 1.663 & 1.708 \\
\hline
\end{tabular}



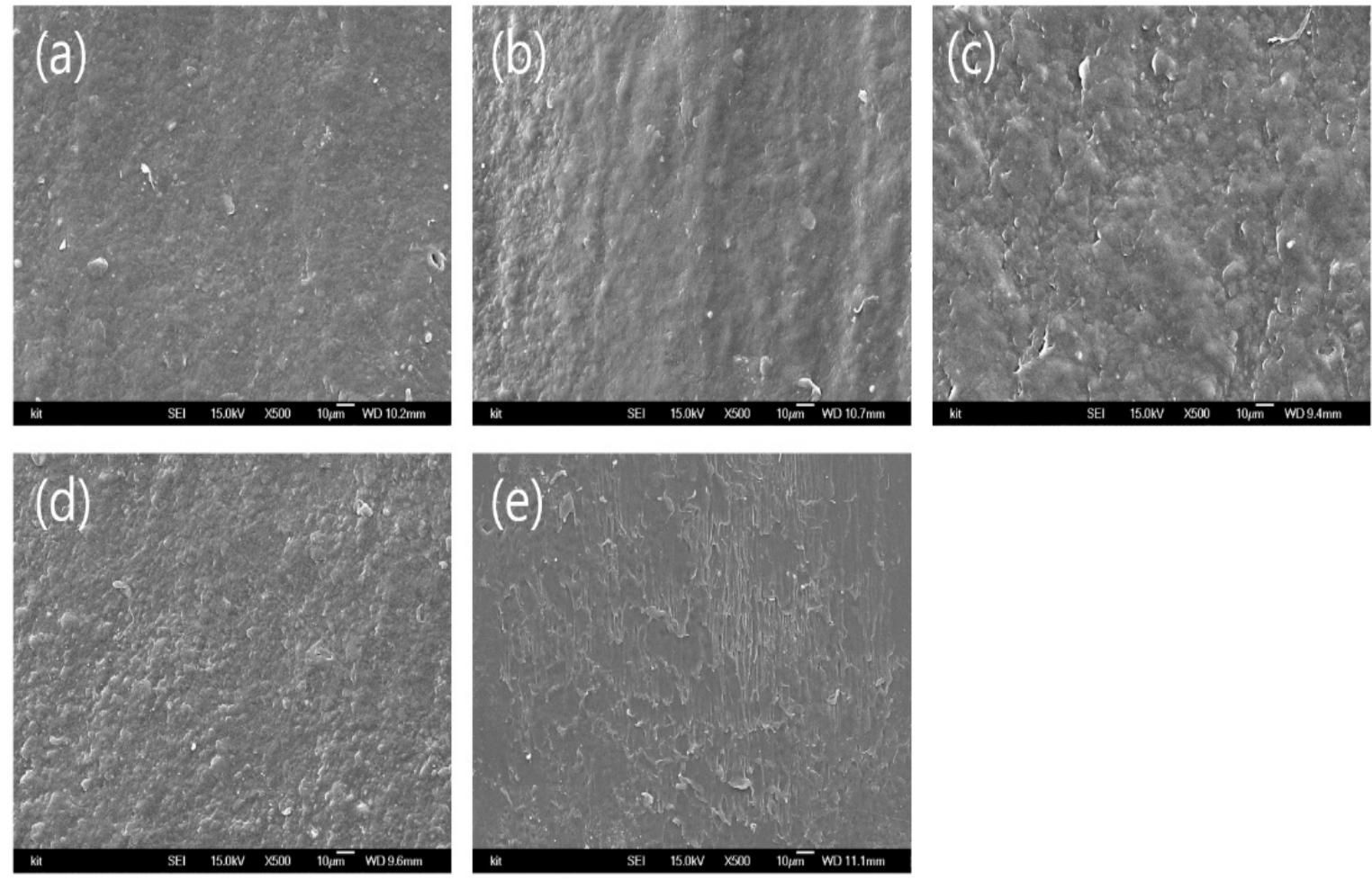

Figure 8. SEM images of polypropylene (PP) aggregate: (a) 0 kGy; (b) 25 kGy; (c) 50 kGy; (d) 75 kGy; (e) 100 kGy.

\subsection{SEM Analysis Results}

The result of SEM analysis, as shown in Figures 8-10, is that a surface of the aggregate itself changed depending on gamma ray irradiation dose, in which a surface change was found through SEM photography. In the case of PP aggregates, a surface change verified through SEM photography was found that as the irradiation dose increased, the surface properties changed more. PE aggregates also showed changes in their surface properties, although they are not as good as PP aggregates. It could be verified changed, but there was no significant change in the surface of ABS aggregate, and it seems that this surface modification was not enough to have an effect on the cement composite. Through this, it was possible to determine why ABS aggregates were not greatly affected by gamma irradiation. According to previous studies, PP and PE among plastic materials were decomposed and crosslinked, respectively, to modify the properties of plastic. However, it was confirmed that PET (polyethylene-terephthalate) or PC (poly-carbonate) was resistant to gamma irradiation effects [11-21]. In the case of ABS, there is no case of gamma irradiation effect; thus, as a result of conducting the experiment, it is judged that PC or PE plastics are resistant to gamma irradiation effects. 

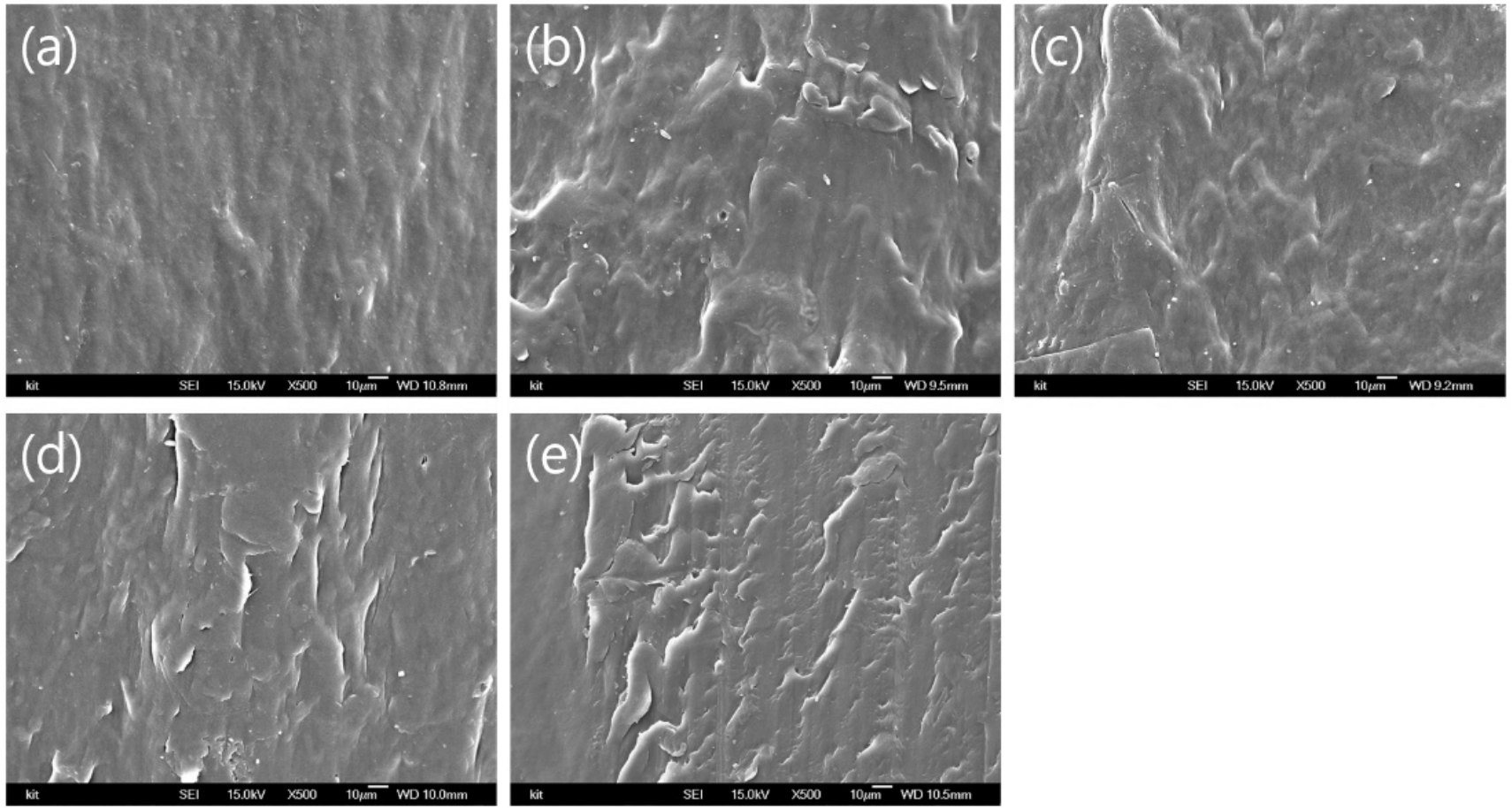

Figure 9. SEM images of polyethylene (PE) aggregate: (a) 0 kGy; (b) 25 kGy; (c) 50 kGy; (d) 75 kGy; (e) 100 kGy.
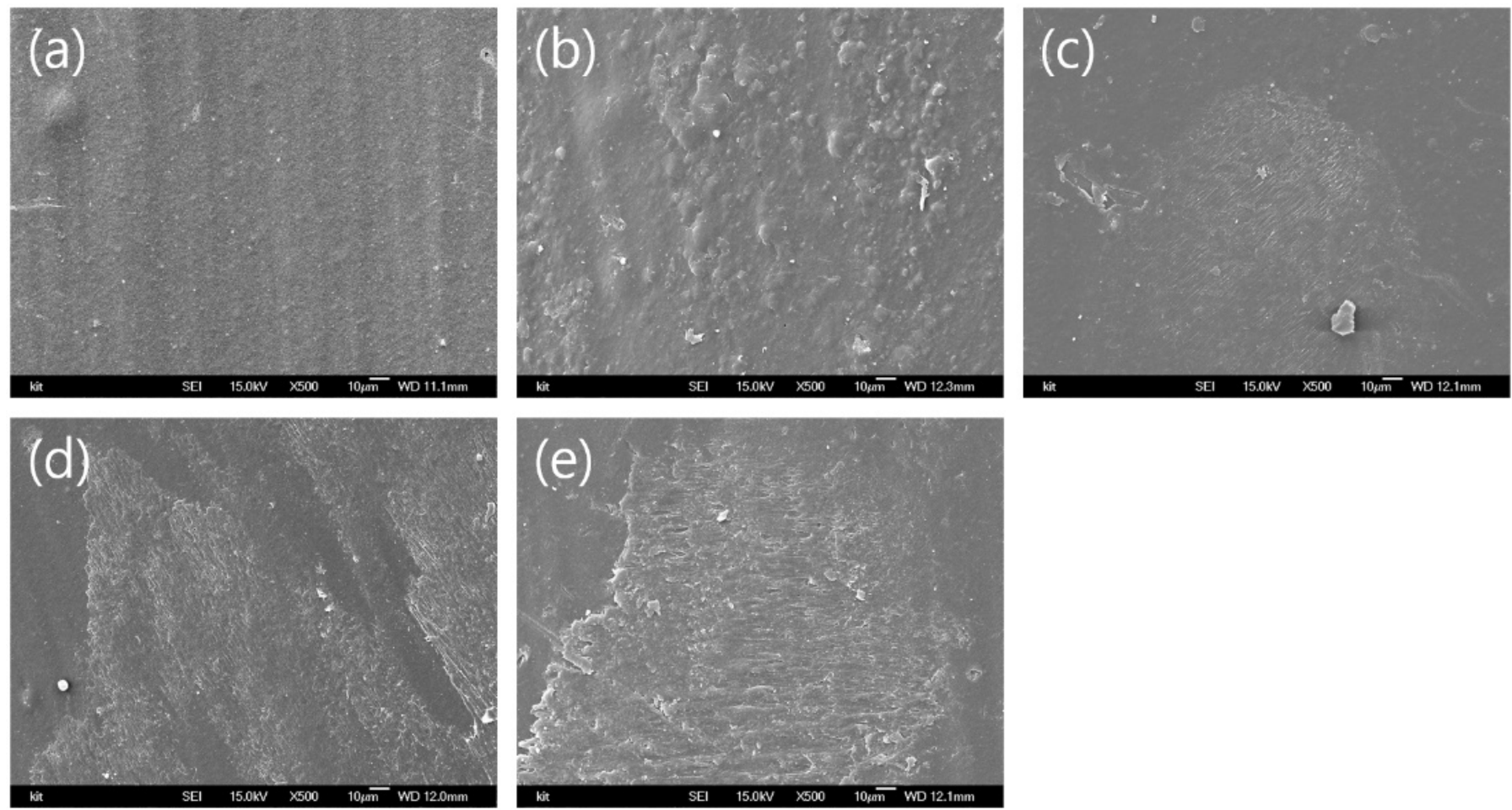

Figure 10. SEM images of acrylonitrile butadiene styrene (ABS) aggregate: (a) 0 kGy; (b) 25 kGy; (c) 50 kGy; (d) 75 kGy; (e) $100 \mathrm{kGy}$.

\subsection{XRD Analysis Results}

Figure 11 shows the results of XRD analysis of PP materials. As a result of the analysis, it was confirmed that the diffraction intensity increased according to the amount of gamma ray irradiation, which is due to the chain cleavage reaction according to the gamma ray irradiation. In addition, as shown in Figure 12, the crystallinity increased linearly according 
to the gamma radiation dose, but at $100 \mathrm{kGy}$, the crystallinity was rather decreased. In conclusion, it was confirmed that the crystallinity of the plastic material was increased and the strength of the cement composite including the gamma irradiation was improved.

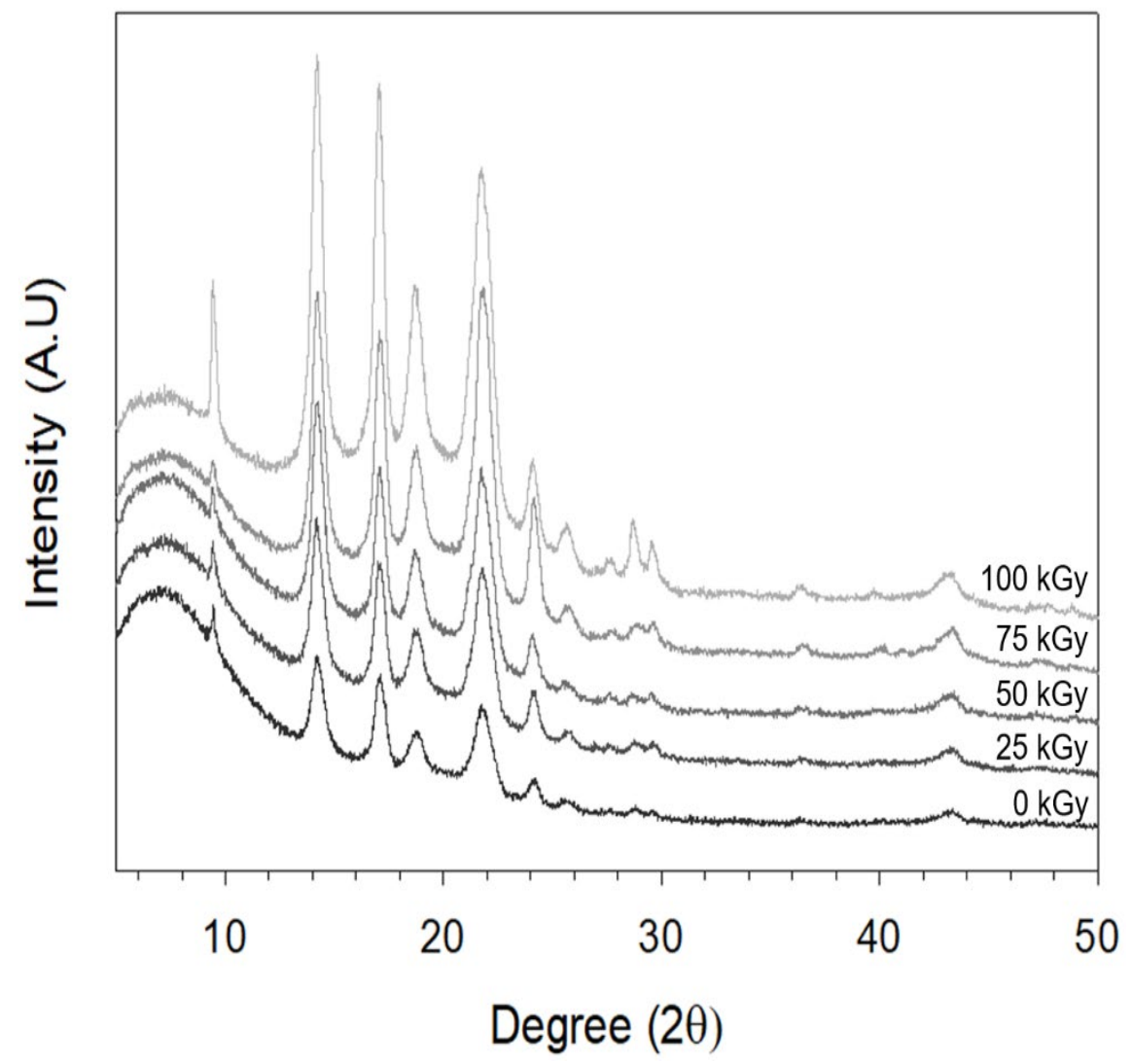

Figure 11. Results of XRD analysis of PP aggregates according to gamma dose.

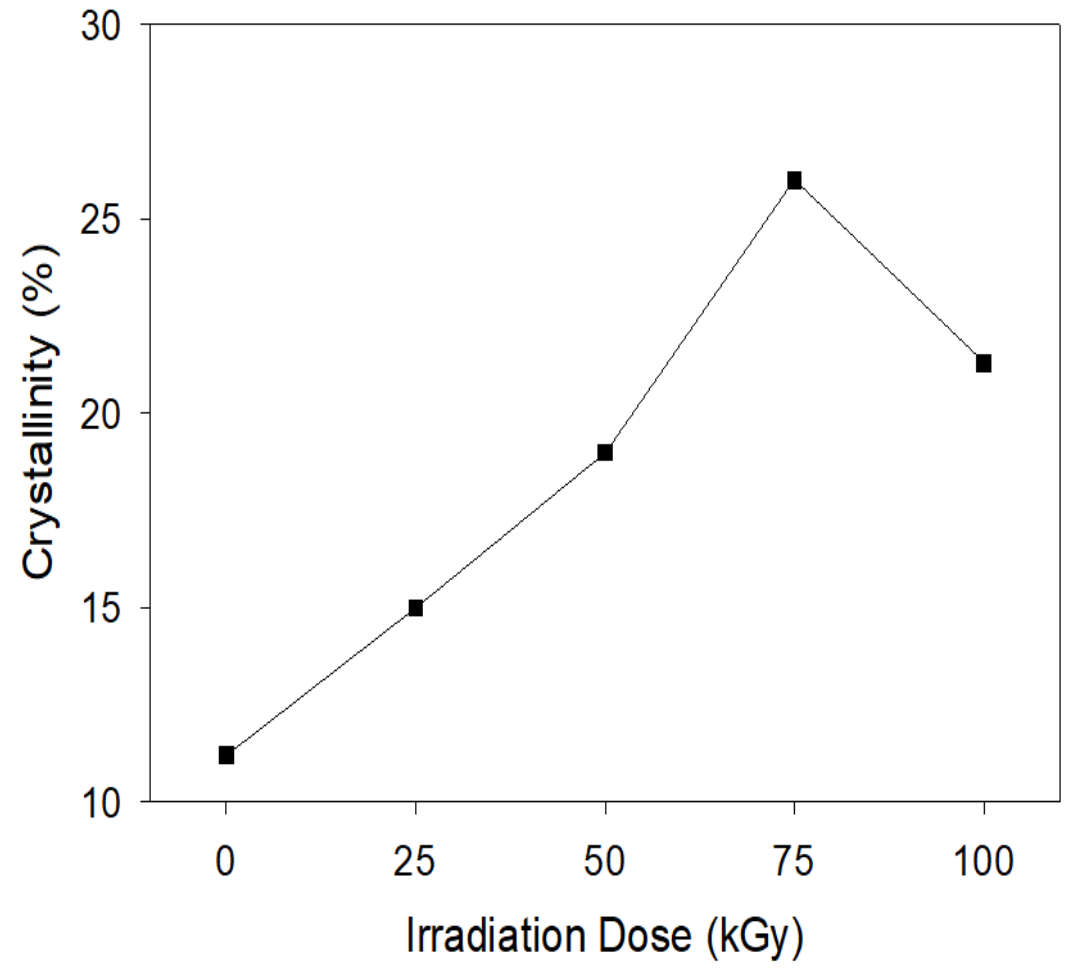

Figure 12. Comparison of crystallinity of PP aggregate according to gamma irradiation dose. 


\section{Conclusions}

In this study, plastic pellets (PP, PE and ABS) induced by crosslinking through gammairradiation technology were substituted to produce cement composites, and their physical performance was evaluated. As a result of the experiment, it was confirmed that there was no significant impact on flexural strength; conversely, it had a significant effect in achieving weight reduction by showing a significant decrease in the unit volume mass. It was determined that there was an effect of gamma irradiation on compressive strength, which increased and decreased according to the irradiation dose.

1. Comparing the compressive strength test results of the cement composites with substitution of PP (poly propylene) pellets induced by crosslinking through gammairradiation technology and PP (poly propylene) pellets without gamma irradiation, it was confirmed that the compressive strength of the PP pellets substituted cement composites increased when PP pellets were irradiated with gamma irradiation dose of $25,50,75$ and $100 \mathrm{kGy}$. The compression strength of the cement composite increased due to the change in the properties of the surface of the plastic pellet where the crosslinking reaction occurred through gamma irradiation resulting in increased adhesion to cement paste. The compressive strength increases further as the strength of the plastic aggregate irradiated with gamma increases, compared to the strength of the plastic aggregate that is not irradiated with gamma rays.

2. Comparing the compressive strength test results of the cement composites with substitution of PE (poly ethylene) pellets induced by crosslinking through gammairradiation technology and PE (poly ethylene) pellets without gamma irradiation, the compressive stress of the cement composite produced by substitution of the plastic pellets irradiated with gamma rays increased as the irradiation dose increased and the compressive stress decreased at $100 \mathrm{kGy}$ as in PP. It is determined that the surface properties of PE aggregates irradiated with gamma rays are modified through crosslinking, which improves the performance between aggregates and pastes, thereby increasing compressive stress and improving the strength of the cement composite.

3. ABS (acrylonitrile butadiene styrene) pellets were found to vary in compressive stress of cement composites when the pellets through gamma irradiation were substituted as aggregates of cement composites. In this case, it is found that the plastic properties of $\mathrm{ABS}$ are resistant to gamma irradiation rather than to crosslinking through gamma irradiation. Conversely, compared to ABS that non-investigated gamma rays, an increase in strength occurred when ABS that irradiated with gamma rays was used, which is considered to require further study.

4. When the cause of the increase in strength of the modified plastic aggregate-substituted cement composite was confirmed through SEM analyzing, in the case of PP or PE, there is the surface change according to gamma irradiation. However, in the case of ABS, no significant change in the surface due to gamma ray irradiation was found. Accordingly, it affects the strength properties, as the surface of the cement composites are modified. Based on the case of ABS, it seems that when gamma-ray irradiation is irradiated, not only the effect of surface modification but also the internal reaction occurs, and through these results, it is considered that further research is necessary.

5. When the flexural strength was analyzed for cement composites using the plastic aggregate modified by gamma ray irradiation, the variables of PP and PE showed a decrease or no tendency. For ABS plastic aggregates, it was possible to confirm the highest bending stress when non-irradiated plastic aggregate was used. In the case of flexural strength compared to the compressive strength, it was confirmed that the results were different from those of the previous experiments. Thus, it is judged that additional experiments are needed.

6. It was confirmed that the crystallinity increased when gamma rays were irradiated to the PP aggregate from an irradiation dose of $0 \mathrm{kGy}$ to an irradiation dose of $75 \mathrm{kGy}$. However, it was confirmed that the crystallinity decreased when the irradiation was 
carried out with an irradiation dose of $100 \mathrm{kGy}$. Conversely, as a result of evaluating the physical properties of the cement composite, it was confirmed that the compressive strength was increased up to $100 \mathrm{kGy}$ as the gamma ray irradiation dose irradiated to the plastic aggregate increased. When compared with the decrease in the crystallinity of aggregates at an irradiation dose of $100 \mathrm{kGy}$, it was judged that additional research is needed on the increase in compressive strength.

7. As a result of conducting a study to modify plastic aggregates using gamma rays, it was confirmed that using gamma ray irradiation technology costs a lot and requires considerable energy. In addition, an investigation was organized and conducted on a method of generating radiation such as gamma rays. Representatively, natural radiation generated from the sun is exemplified; however, there have been several problems. First, there is a need for a device that transmits only gamma rays among radiation. Second, it is difficult to determine the irradiation dose even if gamma rays can be irradiated. For the above two reasons, it is judged that additional research is needed on the method of irradiating gamma rays and measuring irradiation dose.

Author Contributions: Conceptualization, H.L., W.K. and Y.K.; formal analysis, H.C. and H.L.; funding acquisition, W.K.; investigation, H.C., H.L. and J.R.; methodology, Y.K. and H.L.; supervision, W.K.; project administration, W.K.; writing-original draft, H.C.; writing-review and editing, H.L., S.R. and W.K. All authors have read and agreed to the published version of the manuscript.

Funding: This research was supported by a grant (21CTAP-C157794-02) from the Infrastructure and Transportation Technology Promotion Research Program, funded by the Ministry of Land, Infrastructure, and Transport of the Korean government.

Institutional Review Board Statement: Not applicable.

Informed Consent Statement: Not applicable.

Data Availability Statement: Not applicable.

Acknowledgments: The authors are grateful for the support of the Ministry of Land, Infrastructure and Transport of the Korean government in the form of a grant (code\# 21CTAP-C157794-02).

Conflicts of Interest: The authors declare no conflict of interest.

\section{References}

1. KS L ISO 679 Methods of Testing Cements-Determination of Strength; Korean Standards \& Certifications: Chungbuk, Korea, 2006.

2. KS F 2476 Standard Test Method for Polymer-Modified Cement Mortar; Korean Standards \& Certifications: Chungbuk, Korea, 2019.

3. Li, X.; Ling, T.-C.; Mo, K.H. Functions and impacts of plastic/rubber wastes as eco-friendly aggregate in concrete-A review. Constr. Build. Mater. 2020, 240, 117869. [CrossRef]

4. Bandara, M.M.H.W.; Mampearachchi, W.K.; Anojan, T. Enhance the properties of concrete using pre-developed burnt clay chips as internally curing concrete aggregate. Case Stud. Constr. Mater. 2019, 11, e00284. [CrossRef]

5. Miller, N.M.; Tehrani, F.M. Mechanical properties of rubberized lightweight aggregate concrete. Constr. Build. Mater. 2017, 147, 264-271. [CrossRef]

6. Alqahtani, F.K.; Zafar, I. Characterization of processed lightweight aggregate and its effect on physical properties of concrete. Constr. Build. Mater. 2019, 230, 116992. [CrossRef]

7. Schaefer, C. Irradiated Recycled Plastic as a Concrete Additive for Improved Chemo-mechanical Properties in Hardened Cement Pastes. Ph.D. Thesis, Department of Nuclear Science and Engineering, Massachusetts Institute of Technology, Cambridge, MA, USA, 18 May 2017.

8. Schaefer, C.E.; Kupwade-Patil, K.; Ortega, M.; Soriano, C.; Büyüköztürk, O.; White, A.E.; Short, M.P. Irradiated recycled plastic as a concrete additive for improved chemo-mechanical properties and lower carbon footprint. Waste Manag. 2017, 71, 426-439. [CrossRef] [PubMed]

9. Martínez-Barrera, G.; López, H.; Castaño, V.M.; Rodríguez, R. Studies on the rubber phase stability in gamma irradiated polystyrene-SBR blends by using FT-IR and Raman spectroscopy. Radiat. Phys. Chem. 2004, 69, 155-162. [CrossRef]

10. Kattan, M. Thermal behavior of gamma-irradiated amorphous poly (ethylene terephthalate) films. Polym. Eng. Sci. 2006, 46, 1374-1377. [CrossRef]

11. Lee, J.D.; Jeong, S.H.; Choi, S.D.; Kim, H.M. Effect of $\gamma$-ray Irradiation on Mechanical Properties of Ultra-High Molecular Weight Polyethylene. J. Korean Soc. Manuf. Prod. 2008, 6, 108-114. 
12. Dziewinski, J.; Zagorski, Z.P. Radiation Chemistry of Polymeric Components of Radioactive Waste. In Proceedings of the 5th International Symposium on Ionizing Radiation and Polymers, Sainte-Adele, QC, Canada, 21-26 September 2002.

13. Kondyurin, A.; Bilek, M. Ion Beam Treatment of Polymers; Elsevier: Amsterdam, The Netherlands, 2008.

14. Zaman, K.; Haji-Saeid, M. Radiation processing technologies: Past, present and future. Radiat. Phys. Chem. 2004, 71, 17-21.

15. Wishart, J.F.; Rao, B.S.M. Radiation Trends in Radiation Chemistry; World Scientific: Singapore, 2010.

16. Makuuchi, K.; Cheng, S. Radiation Processing of Polymer Materials and Its Industrial Applications; John Wiley and Sons, Inc.: Hoboken, NJ, USA, 2012.

17. Kerluke, D.; Cheng, S.; Cleland, M. X-ray Processing of Advanced Composites at 5MeV and above. In Proceedings of the 47th Society for the Advancement of Materials and Process Engineering (SAMPE) Symposium and Exgibition, Long Beach, CA, USA, 12-16 May 2002.

18. Nasef, M.M.; Guven, O. Radiation-grafted copolyemrs for separation and purification purposes: Status challenges and future directions. Prog. Polym. Sci. 2012, 37, 1597-1656. [CrossRef]

19. Samuel, A.H.; Magee, J.L. Theory of radiation chemistry, II. Track effects in radiolysis of water. J. Chem. Phys. 1953, 21, 1080. [CrossRef]

20. Chemielewski, A.; Haji-Saeid, M.; Ahmed, S. Progress in radiation processing of polymers. Nucl. Instrum. Meth. B 2005, 236, 44-54. [CrossRef]

21. Berejka, A.J.; Everle, C. Electron Beam Curing of Composites in North America. Radiat. Phys. Chem. 2002, 63, 551-556. [CrossRef] 